\title{
Estimation of Optimum Time of Spray for Controlling Rice Leaf Folder Infestation on Boro Rice in Terai Region of West Bengal Using Best Fitted Linear and Nonlinear Growth Model
}

\author{
Soumitra Sankar Das ${ }^{1 *}$, Manoj Kanti Debnath ${ }^{1}$, Satyananda Basak ${ }^{1}$, \\ Joydeb Ghosh ${ }^{2}$ and Aparajita Das $^{3}$
}

${ }^{1}$ Department of Agricultural Statistics, ${ }^{2}$ Department of Entomology, ${ }^{3}$ Department of Genetics and Plant Breeding, UBKV, Pundibari, West Bengal, 736165, India

*Corresponding author

\author{
A B S T R A C T
}

\section{Keywords \\ Nonlinear models, MAPE, Akaike's Information Criteria, Bayesian Information Criterion, and Rice leaf folder. \\ Article Info \\ Accepted: \\ 26 May 2017 \\ Available Online: \\ 10 June 2017}

The modeling of insects/pests population dynamics is to understand how the respective population change arises owing to the interplay of environmental forces, density dependent regulation and inherent stochasticity imbibed in the system. Enormous applications of such modeling are found in natural science. It is quite obvious that excess zeros are common phenomenon in counting insects. If data is not properly modelled, these properties can invalidate the normal distribution assumptions resulting in biased estimation of parameters and distress the integrity of the scientific inferences. Therefore, it is recommended that statistical models appropriate for handling such data and selecting appropriate model to ensure efficient statistical inference. Hence, a study has been undertaken to model the occurrence of rice leaf folder infestation on boro rice, at Terai region. This study provides the basic needs of parameter estimations for different fitted linear and nonlinear models, determination of undertaking optimum time of plant protection measures. Based on different model selection criterion, Cubic model is found to be the best and accordingly determine the optimum time i.e. $60 \mathrm{DAT}$, when any plant protection measure to be adopted in the field.

\section{Introduction}

The rice crop provides food to more than half of the world's population and hosts to over 800 species of insect herbivores from nursery to harvest but only a few of them are of potential threat and have gained the major importance as for as losses in yields caused by them, are concerned (Cramer, 1967; Karim and Riazuddin, 1999). The present study area falls in the Terai Agro-climatic zone of North Bengal where Rice and Potato are the two major widely grown crops. Rice is grown both as Boro and as Aman crop (season specific). Rice leaf folder is a common pest of rice. The rice leaf folder lifecycle is $25-35$ days (egg 6-7, larva 15-25, pupa 6-8 and preovi position 2-7). The young and green rice plants are more severely infested. Satish et al., (2007) conducted a three-year study and found that leaf folder incidence on rice was $1.2-20.5 \%$ folded leaves with highest infestation between 45-55 DAT. The control of these insects pest has often relied on the extensive use of insecticides, which disrupt the beneficial insects and other insect fauna 
besides causing environmental pollution (Heong, 2005).

The objective of modeling the dynamics of any population (of insects/pests) is to understand how the respective population change arises owing to the interplay of environmental forces, density dependent regulation \& inherent stochasticity imbibed in the system. Growth model methodology has been widely used in the modelling-work on plant/pest growth. Since growth of living organisms are usually nonlinear, it is reasonable to explore the use of non-linear growth models to represent the growth process of the pests (Basak et al., 2017).

Nonlinear modelling of rice leaf folder infestation on Boro rice was pointed out by Basak et al., (2017). Different parametric and non-parametric models for the infestation data of the pests (Thrips, Jassids, Whitefly, Borer) on Brinjal, and pests (Whitefly, Yellow Mite, Thrips) on Chilli for the period (September, 2007 to March, 2008) were fitted by Pal et al., (2012). Fitting of Different Non-linear and Parametric Model for the Incidence of Mango hopper was also carried out by Debnath et al., (2015). Very few studies have been conducted regarding model fitting for the insect pest infestation so far. Realizing the significance of the rice leaf folderincidence on boro rice, a study has been carried out to find the appropriate statistical model and to estimate the suitable time for applying the plant protection measure.

\section{Materials and Methods}

The field experiment was conducted at Uttar Banga Krishi Viswavidyalaya (UBKV), Pundibari, Coochbehar, West Bengal university farm where seed sowing of Boro rice (var. Satabdi) were initiated on $25^{\text {th }} \mathrm{Feb}$, 2014 at the nursery bed and transplanting was done on $25^{\text {th }}$ March, 2014. The recording of the data was initiated on $5^{\text {th }}$ May, 2014 and it was continued up to $16^{\text {th }}$ June, 2014. Harvesting of the crop was done on $28^{\text {th }}$ June, 2014. At first, the field is divided into 4 numbers of strata and from each stratum, coordinates were randomly chosen using random number table for selecting the one square meter area. Size of the plot was $15 \mathrm{X}$ 10 square meter. For this study, seven (7) coordinates per stratum were chosen for collecting Rice leaf folder (RFL) infestation data from Boro rice field and all plants in each square unit area were checked and recorded for the presence of number of pests. Different linear and nonlinear growth model were fitted to the RFL infestation data for identifying the best fitted model which are presented in table 1.Nonlinear models are more difficult to specify and estimate than linear models and the solutions are determined iteratively (Draper and Smith, 1981; Ratkowskay,1983). The iterative method used for the estimation of parameter in the nonlinear model is the Marquardt method (Draper and Smith, 1981).

This study considers several procedures to test the goodness of fit for nonlinear model, such as residuals analysis and normal probability plots (Q-Q plot). The Mean Square Error (MSE), Mean Absolute Error (MAE), Mean Absolute Percentage Error (MAPE), Akaike's Information Criteria (AIC), Bayesian Information Criterion (BIC) and Average Relative Predictive Error (ARPE) were used to measure the model performance.

MAE takes the absolute value of forecast and averages them over the entirely of the forecast time period.

Taking an absolute value of an observation disregards whether the observation is negative or positive and in this case avoids the positive and negatives cancelling each other out. 
$M A E=\frac{1}{N} \sum_{k=1}^{N}\left|F_{k}-A_{k}\right| \cdot$ MAPE is the average absolute percentage error for each time period or forecast minus actual divided by actual i.e. $M A P E=\frac{1}{N} \sum_{k=1}^{N} \frac{\left|F_{k}-A_{k}\right|}{A_{k}}$.

\section{Akaike's Information Criteria (AIC)}

\section{The general form for calculating AIC}

$A I C=-2 \ln ($ likelihood $)+2 K$, Where, $\ln$ is the natural logarithm, (likelihood) is the value of the likelihood and $\mathrm{K}$ is the number of parameters in the model. AIC can also be calculated using residual sums of squares from regression i.e. $A I C=n \ln \left(\frac{R S S}{n}\right)+2 k$, Where, nis the number of data points (observations) and RSS is the residual sums of squares.

\section{Bayesian Information Criterion (BIC)}

The BIC is an increasing function of the error variance $\sigma_{e}^{2}$ and an increasing function of $k$. That is, unexplained variation in the dependent variable and the number of explanatory variables increases the value of BIC. Hence, lower BIC implies either fewer explanatory variables, better fit, or both. In terms of the residual sum of squares (RSS) the $\mathrm{BIC}$ is $B I C=n \ln \left(\frac{R S S}{n}\right)+k \ln (n)$, where, $\mathrm{k}$ is the number of model parameters in the test.

Average Relative Predictive Error (ARPE) $=\frac{1}{n} \sum \frac{\left|\hat{y}_{i}-y_{i}\right|}{y_{i}}, \quad$ Where, $\hat{y}_{i}$ is predicted observation and $y_{i}$ is the original observation.

The two main assumptions of randomness and normality of residuals are examined by using the well-known run test and Shapiro-Wilk test respectively (Prajneshu, 1998). The models were diagnosed using error analysis. The error analysis is performed to analyze difference between the error values and the estimated values of observation. This analysis is able to investigate the goodness of fit of the nonlinear models graphically which have been illustrated in this paper. The scatter plot of the error is important in deciding whether the residual values are uniformly distributed, there is no systematic trend of the residual values or the variance is constant or not. If the error plot showed that the errors have a homogenous variance then the models are adequate to model the data.

\section{Estimation of $\mathbf{t}_{\mathrm{opt}}$. And $\mathbf{t}_{\max }$.}

Based on best fitted model, the (i) point of time when rate of growth of the pests is at its peak i.e. $\mathrm{t}_{\mathrm{opt}}$. And (ii) point of time when pest infestation is at its maximum i.e. $\mathrm{t}_{\max }$. Were calculated. Here $t_{\text {opt }}$ is useful as it indicates the point of time when any protection measure will be most effective and $t_{\max }$ is the point of time when maximum pest or disease build up occurs in the field.

\section{Results and Discussion}

The collected data are first subjected to two way analysis of variance. Effects of two factors namely, date and stratums along with their interactions are studied for their significance which is presented in the tables 1. From the ANOVA table it can be seen that stratum does not differ significantly. The significant difference was found only for date effect. Since no stratum to stratum variation is observed data can be pooled for further analysis.

The RLF pest populations were allowed to grow in its natural way as no remedial measure like insecticidal spray was adopted. The pest data obtained from the rice field are 
plotted against time. The scatter plot obtained for the data shows that pest infestation in the field increases linearly throughout the growing season of the crop. For the whole field the RLF count starts with 0.642 at the first date of observation i.e. 69 days crop and ends with 6.39 at the last date of observation i.e. 110 days crop.

The various models discussed in this paper are actually fitted for RLF data. For fitting the non-linear growth models, the average values of the data obtained from each stratum were considered. Statistical significance of the parameters of the non-linear model was determined by the evaluating the $95 \%$ confidence intervals of the estimated parameter.

The null hypothesis $\mathrm{H}_{0}$ : (all the parameters $=0)$ was rejected when $95 \%$ confidence intervals of the estimated parameters does not include zero.

\section{Identifying the best fitted non-linear Model}

The data on RFL infestation are fitted by different linear and nonlinear models. From the table 3 it can be seen that all the models have given good fit and their $\mathrm{R}^{2}$ values are more or less approximately similar.

However, cubic model give the best fit in respect of $\mathrm{R}^{2}$ values followed by Gompertz model.

The cubic model produces a significantly smaller Mean Square Error (0.022), Mean absolute error (0.108) and Mean absolute percentage error (0.041) followed by Gompertz model. Similarly, Cubic model also gives the lower AIC (-57.993) and BIC (60.826) values that imply for better fit of the model. In terms of ARPE, it can be seen that all the models have given good fit because the ARPE values are less than $10 \%$.

Table.1a Different linear and nonlinear growth models with their

Corresponding probability function

\begin{tabular}{|c|c|c|}
\hline SL. No. & Models & Probability functions \\
\hline 1. & $\begin{array}{l}\text { Linear } \\
\text { (Draper and smith 1981) }\end{array}$ & $y=\alpha+\beta t+e$ \\
\hline 2. & Cubic & $y=\alpha+\beta t+\gamma t^{2}+\delta t^{3}+e$ \\
\hline 3. & $\begin{array}{l}\text { Logistic } \\
\text { (Nelder 1961, Oliver 1964) }\end{array}$ & $y=\frac{\alpha}{\left(1+\beta e^{-k t}\right)}+e$ \\
\hline 4. & $\begin{array}{l}\text { Gompertz } \\
\text { (Draper and smith 1981) }\end{array}$ & $y=\alpha e^{-\beta e^{-k^{*} t}}+e$ \\
\hline 5. & Malthus model & $y=\alpha e^{k t}+e$ \\
\hline 6. & $\begin{array}{l}\text { Monomolecular model } \\
\text { (Draper and smith 1981) }\end{array}$ & $y=\alpha\left(1-\beta e^{-k t}\right)+e$ \\
\hline 7. & $\begin{array}{l}\text { Richards model } \\
\text { (Richards 1959, Myers 1986) }\end{array}$ & $y=\frac{\alpha}{\left(1+\beta e^{-k t}\right)^{\frac{1}{m}}}+e$ \\
\hline 8. & Quadratic & $y=\alpha+\beta t+\gamma t^{2}+e$ \\
\hline
\end{tabular}


Table.1b ANOVA table of RLF pest infestation during the study period

\begin{tabular}{|c|c|c|c|c|c|c|}
\hline $\begin{array}{l}\text { Source of } \\
\text { Variation }\end{array}$ & $\begin{array}{l}\text { Degrees of } \\
\text { Freedom }\end{array}$ & $\begin{array}{l}\text { Sum of } \\
\text { Square }\end{array}$ & $\begin{array}{l}\text { Mean Sum } \\
\text { of Square }\end{array}$ & $\begin{array}{l}\text { F Ratio } \\
\text { (cal) }\end{array}$ & $\mathrm{F}_{\mathrm{tab}}$ & $\begin{array}{l}\text { Critical } \\
\text { Difference }\end{array}$ \\
\hline Due to date & 14 & 1415.48 & 101.11 & $83.43^{*}$ & 1.72 & 10.57 \\
\hline Due to stratum & 3 & 1.074 & 0.36 & 0.29 & & \\
\hline Interaction & 42 & 8.677 & 0.21 & 0.170 & & \\
\hline Error & 360 & 436.29 & 1.21 & & & \\
\hline Total & 419 & 1861.51 & & & & \\
\hline
\end{tabular}

Table.2 Parameter estimates of different linear and non-linear growth models for rice leaf folder

\begin{tabular}{|c|c|c|c|c|c|}
\hline \multirow[b]{2}{*}{ Models Name } & \multirow[b]{2}{*}{ Parameters } & \multirow[b]{2}{*}{ Estimate } & \multirow[b]{2}{*}{ Std. Error } & \multicolumn{2}{|c|}{ 95\% Confidence Interval } \\
\hline & & & & $\begin{array}{l}\text { Lower } \\
\text { Bound }\end{array}$ & Upper Bound \\
\hline \multirow{3}{*}{ Logistic } & $\alpha$ & 7.052 & 0.236 & 6.547 & 7.558 \\
\hline & $\beta$ & 7.032 & 0.614 & 5.716 & 8.349 \\
\hline & $\mathrm{k}$ & 0.283 & 0.019 & 0.241 & 0.325 \\
\hline \multirow{3}{*}{ Gompertz } & $\alpha$ & 7.870 & 0.353 & 7.113 & 8.626 \\
\hline & $\beta$ & 2.442 & 0.093 & 2.244 & 2.641 \\
\hline & $\mathrm{k}$ & 0.165 & 0.013 & 0.137 & 0.193 \\
\hline \multirow{3}{*}{ Monomolecular } & $\alpha$ & 14.34 & 2.962 & 7.986 & 20.692 \\
\hline & $\beta$ & 0.971 & 0.007 & 0.956 & 0.986 \\
\hline & $\mathrm{k}$ & 0.038 & 0.011 & 0.015 & 0.061 \\
\hline \multirow{4}{*}{ Richard's } & $\alpha$ & $1.586 \mathrm{E} 3$ & $1.955 \mathrm{E} 9$ & $-4.225 \mathrm{E} 9$ & $4.225 \mathrm{E} 9$ \\
\hline & $\beta$ & 7.025 & 0.666 & 5.585 & 8.464 \\
\hline & $\mathrm{k}$ & 0.285 & 0.021 & 0.239 & 0.331 \\
\hline & $\mathrm{m}$ & 226.315 & $2.790 \mathrm{E} 8$ & $-6.027 \mathrm{E} 8$ & $6.027 \mathrm{E} 8$ \\
\hline \multirow{2}{*}{ Linear } & $\alpha$ & 0.730 & 0.118 & 0.480 & 0.981 \\
\hline & $\beta$ & 0.395 & 0.013 & 0.369 & 0.422 \\
\hline \multirow{4}{*}{ Cubic } & $\alpha$ & 0.595 & 0.118 & 0.341 & 0.849 \\
\hline & $\beta$ & 0.358 & 0.066 & 0.217 & 0.500 \\
\hline & $Y$ & 0.019 & 0.010 & -0.002 & 0.040 \\
\hline & $\delta$ & -0.001 & 0.000 & -0.002 & 0.000 \\
\hline \multirow{3}{*}{ Quadratic } & $\alpha$ & 0.409 & 0.118 & 0.156 & 0.661 \\
\hline & $\beta$ & 0.524 & 0.034 & 0.451 & 0.597 \\
\hline & $Y$ & -0.008 & 0.002 & -0.012 & -0.004 \\
\hline
\end{tabular}


Table.3 Model selection criterion of different linear and non-linear Growth models for rice leaf folder

\begin{tabular}{llllllll}
\hline Model & $\mathbf{R}^{\mathbf{2}}$ & MSE & MAE & MAPE & AIC & BIC & ARPE \\
\hline Cubic & $\mathbf{0 . 9 9 6}$ & $\mathbf{0 . 0 2 2}$ & $\mathbf{0 . 1 0 8}$ & $\mathbf{0 . 0 4 1}$ & $\mathbf{- 5 7 . 9 9 3}$ & $\mathbf{- 6 0 . 8 2 6}$ & $\mathbf{4 . 3 7 9}$ \\
Gompertz & 0.994 & 0.028 & 0.123 & 0.045 & -56.501 & -55.848 & 4.810 \\
Quadratic & 0.993 & 0.033 & 0.123 & 0.053 & -53.519 & -55.699 & 5.658 \\
Logistic & 0.992 & 0.038 & 0.147 & 0.077 & -51.015 & -50.362 & 8.119 \\
Monomolecular & 0.992 & 0.035 & 0.124 & 0.054 & -52.376 & -51.723 & 5.681 \\
Richards & 0.992 & 0.042 & 0.147 & 0.076 & -47.275 & -47.275 & 8.052 \\
Linear & 0.985 & 0.064 & 0.169 & 0.065 & -43.966 & -43.157 & 6.904 \\
\hline
\end{tabular}

Table.4 Runs Test for Cubic and GompertzModel for RLF data

\begin{tabular}{llllllll}
\hline \multirow{2}{*}{ Model } & $\begin{array}{l}\text { Test } \\
\text { Value }^{\mathrm{a}}\end{array}$ & $\begin{array}{l}\text { Cases } \\
\text { Test } \\
\text { Value }\end{array}$ & $\begin{array}{l}\text { Cases } \\
\text { Value Test } \\
\text { Value }\end{array}$ & $\begin{array}{l}\text { Total } \\
\text { Cases }\end{array}$ & $\begin{array}{l}\text { Number } \\
\text { of Runs }\end{array}$ & Z & $\begin{array}{l}\text { Asymp. } \\
\text { Sig. (2- } \\
\text { tailed) }\end{array}$ \\
\hline Cubic & -0.019 & 8 & 9 & 17 & 6 & -1.49 & 0.135 \\
Gompertz & -0.020 & 8 & 9 & 17 & 5 & -1.99 & 0.046 \\
\hline a = median & & & & & & &
\end{tabular}

Table.5 Normality test of the residuals for Cubic and Gompertz model

\begin{tabular}{lllllllll}
\hline Models & \multicolumn{6}{l}{ Kolmogorov-Smirnov $(\mathrm{K}-\mathrm{S})$} & \multicolumn{5}{l}{ Shapiro-Wilk (W-test) } \\
\cline { 2 - 9 } & Statistic & df & Table value & Sig. & Statistic & df & Table value & Sig. \\
\hline Cubic & 0.164 & 17 & 0.3179 & 0.200 & 0.932 & 17 & 0.892 & 0.234 \\
\hline Gompertz & 0.159 & 17 & 0.3179 & 0.200 & 0.942 & 17 & 0.892 & 0.341 \\
\hline
\end{tabular}

Table.6 Predicted values of rice leaf folder data using cubic model

\begin{tabular}{llllll}
\hline Time & DAT & $\begin{array}{l}\text { Cubic } \\
\text { (Predicted) }\end{array}$ & Time & DAT & $\begin{array}{l}\text { Cubic } \\
\text { (Predicted) }\end{array}$ \\
\hline 0 & 41 & 0.60 & 9 & 68 & 4.52 \\
1 & 44 & 0.97 & 10 & 71 & 4.93 \\
2 & 47 & 1.38 & 11 & 74 & 5.31 \\
3 & 50 & 1.81 & 12 & 77 & 5.66 \\
4 & 53 & 2.26 & 13 & 80 & 5.96 \\
5 & 56 & 2.71 & 14 & 83 & 6.21 \\
6 & 59 & 3.18 & 15 & 86 & 6.41 \\
$\mathbf{6 . 3}$ & $\mathbf{5 9 . 9}$ & $\mathbf{3 . 3 5}$ & 16 & 89 & 6.55 \\
7 & 62 & 3.64 & $\mathbf{1 9}$ & $\mathbf{9 8}$ & $\mathbf{7 . 4}$ \\
8 & 65 & 4.09 & & & \\
\hline
\end{tabular}


Fig.1 Scatter plot of incidence of RLF pest incidence vs. time

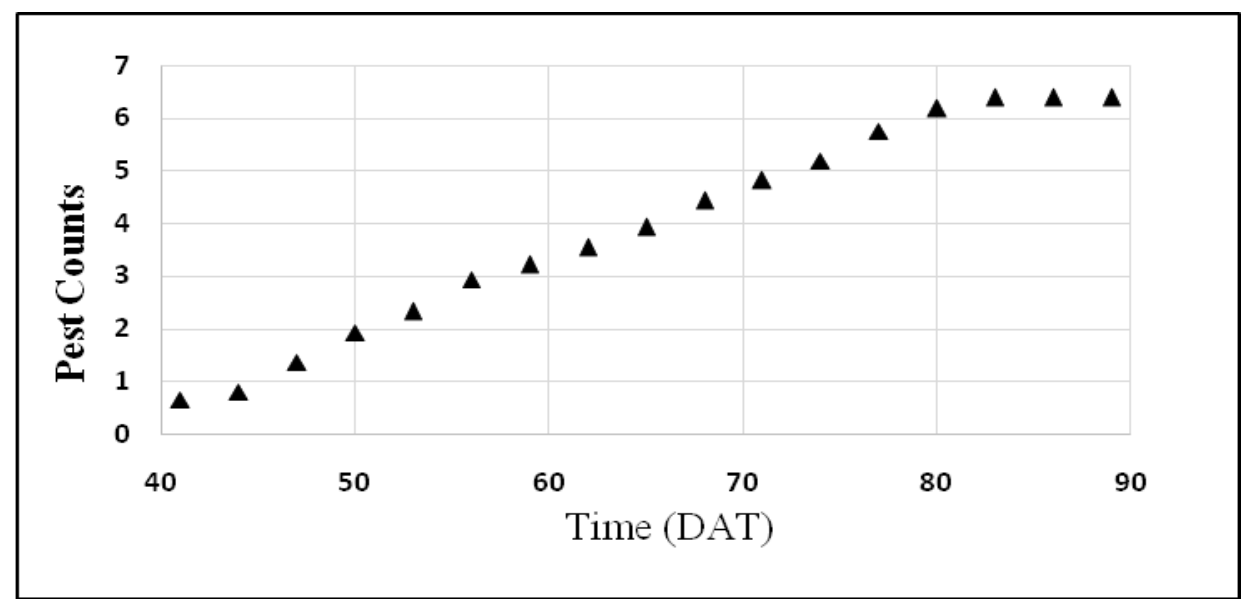

Fig.2 Residual plots for cubic and Gompertz model
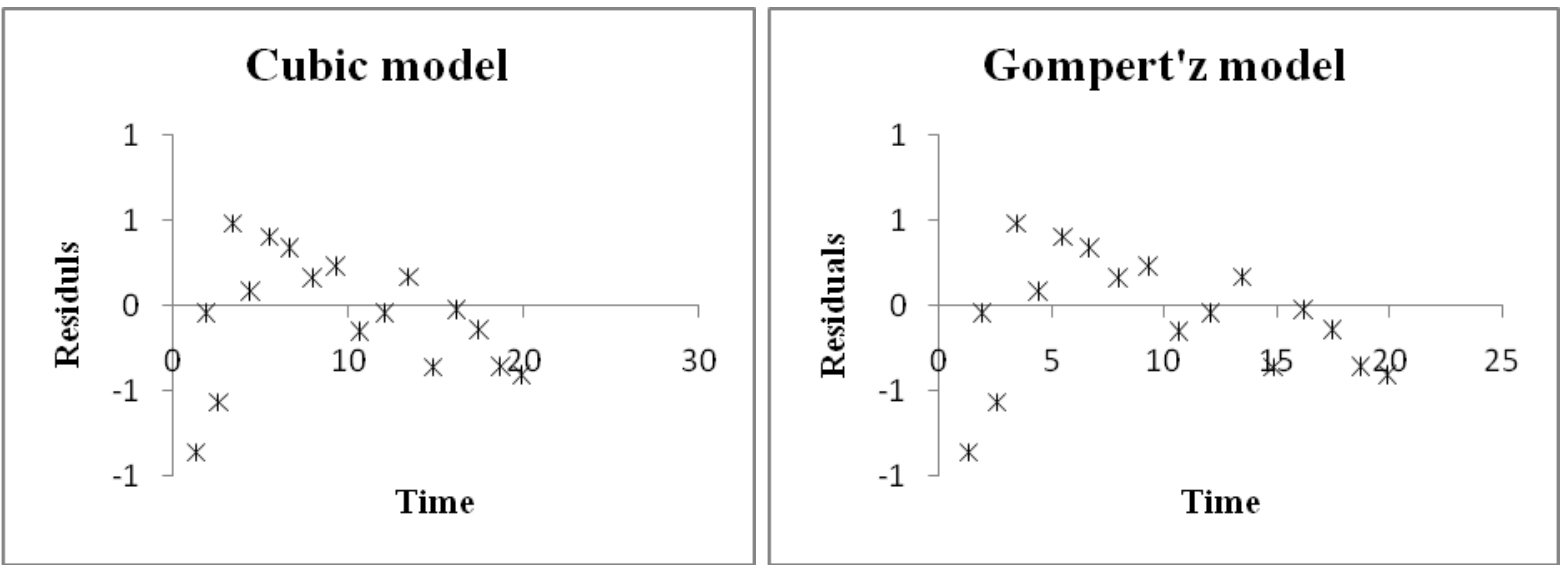

Fig.3 Normal Q-Q plot of the residuals for Cubic (a) and Gompertz (b) model
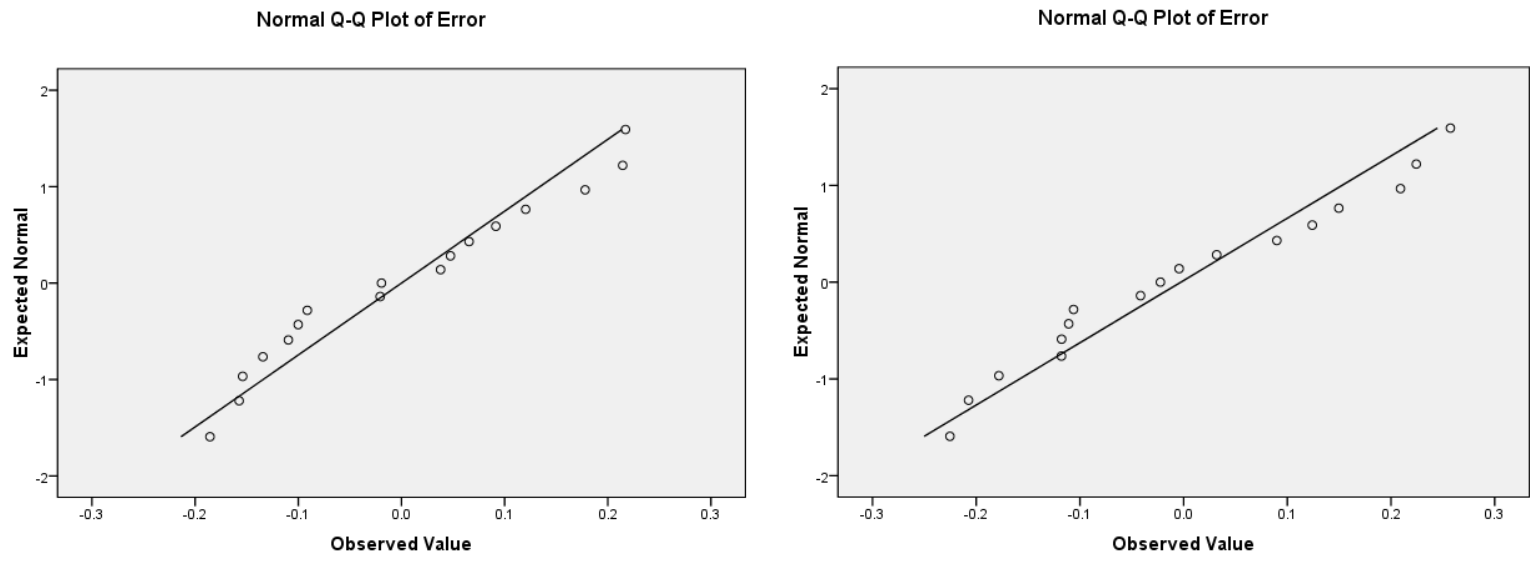

a

b 
Fig.4 Plot of residual vs. estimated valuesfor Cubic andGompertz model

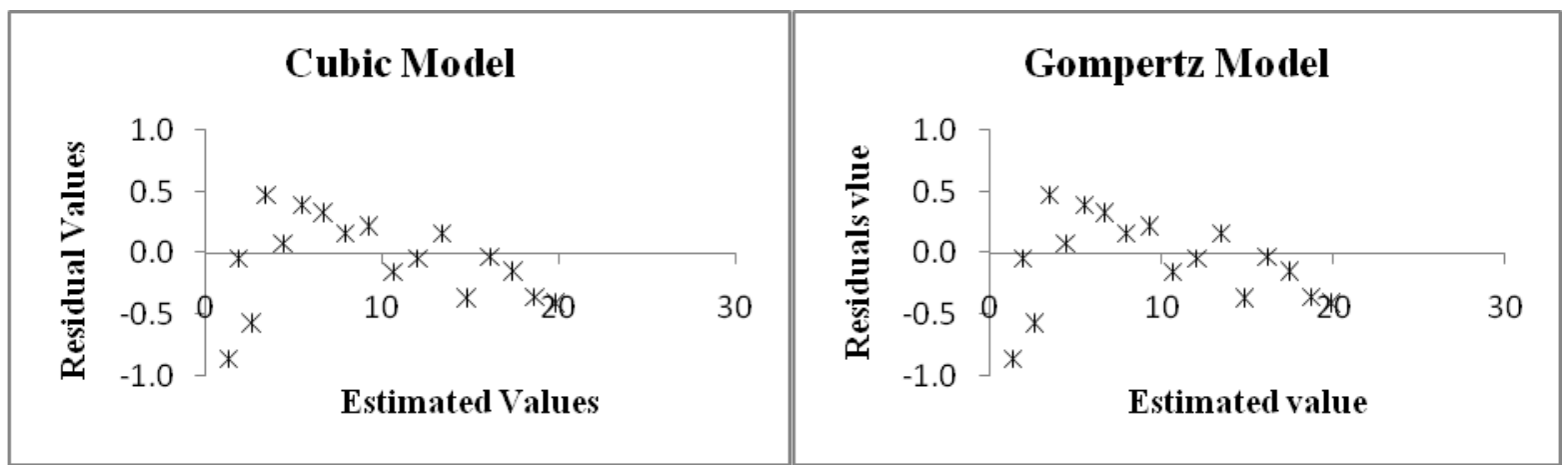

The plotted residuals of the fitted nonlinear models are shown in figure 2 . The plots show that the residuals are distributed mostly uniformly along with the zero line and no systematic pattern is visible which indicate that the residuals from the fitted models are random or independent.

For testing the randomness of the residual for the best fitted model, run test have been performed. To carry out run test the residuals are replace by positive (+) and negative (-) sign. For cubic and Gompartz, there are 9+ signs $\left(=N_{1}\right)$ and $8-$ signs $\left(=N_{2}\right)$. The critical values of runs at the 0.05 level of significance are 5 and 14 which are obtained from the Tableon run test statistic. From the table 4, it can be seen that the number of runs is greater than 5and less than 14. So the observed sequences of residuals can be considered to be random.

To test the normality of residuals obtained from cubic and Gompertz model, Kolmogorov-Smirnov (K-S) and ShapiroWilk (W-test) test has been performed and are shown in table 5.

The calculated value of the K-S test statistic for Cubic and Gompertz model are 0.164 and 0.159 respectively. Since the calculated value of $\mathrm{D}_{\mathrm{n} \text { (Cal.) }}<\mathrm{D}_{\mathrm{n} \text { (Tab.), } 0.05=0.31796 \text {, the null }}$ hypothesis i.e. the observed distribution is Normal, is accepted. In case of the Shapiro-
Wilk test, the calculated value of the statistic for Cubic and Gompertz model is 0.932 and 0.942 respectively. As the calculated value of $\mathrm{W}$ (Cal.) $>\mathrm{W}$ (Tab.), $0.05=0.892$, the null hypothesis i.e. the observed distribution is Normal, is accepted. Thus it can be concluded that the residuals are normally distributed. The normal Q-Q plots also support this and are presented in the figure 3 .

The plots of residual vs. estimated values based on RLF data for Cubic and Gompertz model are depicted in the figure 4 . The figure shows that most of the values lie around the zero lines except 2 to 3 value which indicates the homogeneity of error variance roughly.

This study found that Cubic model followed by Gompertz model has the ability and suitability for quantifying the RLF pest infestation rate in Rice field over time. Hence in equation form the best fitted model i.e. Cubic model are represented as $y=0.595+0.358 * t+0.019 * t^{2}-0.001 * t^{3}$

Similar study has also been carried out on insect pest infestation by Basak et al., (2017), Debnath et al., (2015) and Pal et al., (2012).Their study reveals that Cubic model is the best model for fitting the insect pest infestation data.

Based on Cubic model, it can be easily find the (i) point of time when rate of growth of 
the pests is at its peak i.e. $\mathrm{t}_{\mathrm{opt}}$. And (ii) point of time when pest infestation is at its maximum i.e. $\mathrm{t}_{\max }$. The results are given as $t_{\text {opt. }}=-\frac{\gamma}{3 \delta}=6.3$ and

$t_{\max .}=-\frac{2 \gamma \pm \sqrt{4 \gamma^{2}-12 \beta \delta}}{6 \delta}=19$

Form the table 6it can be seen that maximum rate of growth of RLF pest in the field occur at around 60 DAT when forecasted pest population in the field is 3.35 which is much below the ETL level. Throughout the growing season of the crop pest population remains much below the ETL level. Hence, it will not be economical to adopt any pesticide spray in the field. Again the maximum RLF population build up (7.4) in the field occurs only at the harvesting stage of the crop.

The distribution of pests provides an insight through which the probability of occurrence of pest incidence with varying quantum can be found. The present study has immense importance to describe the growth pattern of the pest, RLF population over time in actual field condition by using linear and non-linear models. Based on the knowledge of the timepoints, (a) when the rate of growth of the pest population assumes maximum and (b) the maximum number of pests, farmer can plan the pest control schedule in accordance with the results emanated from the analysis. After the analysis and interpretation of typical data-set generated under the experiment considered in this paper, the non-deterministic cubic model found to be highly precise and the values of the parameters (time-point corresponding to the maximum rate of growth and the time-point corresponding to the maximum pest population) are found to be 60 DAT and 90 DAT respectively. Though, in this case the ETL level for the pest population has not reached, the most fortune time to adopt control measure can be formulated. ETL levels are not always reached because of existence of temporal and spatial variation in case of pest infestation. Therefore, the present study aids in formulating forewarning system against rice leaf folder incidence.

\section{Acknowledgement}

Funding from UGC (Rajiv Gandhi National Fellowship), New Delhi and UBKV farm for this research work is duly acknowledged.

\section{References}

Basak, S., Das, S. S., and Pal, S. 2017. Nonlinear modelling of rice leaf folder infestation on Boro rice in Pundibari (A part of Cooch Behar district). Journal of Entomology and Zoology Studies. 5(2): 967-972.

Cramer, H.H. 1967. La Protection des Planteset des Recoltesdans le Monde. Bayer P flanzenschutz, Leverkusen.

Draper, N.R. and Smith, H. 1981. Applied regression analysis. 2nd edition. John Wiley \& Sons Inc. New York. 709 p.

Heong, K.L., and Escalada, M.M. 2005. Scaling up communication of scientific information to rural communities. J. Sci. Commun. 4(3):1-3.

Karim, S., and Riazuddin, S. 1999. Rice Insect Pest of Pakistan and Their Control. A Lesson from Past and Sustainable Future Integrated Pest Management. Pakistan Journal of Biological Sciences.2 (2): 261-276.

Myers, R.H. 1986. Classical and modern regression with applications. Duxubury Press, Boston. 359 p.

Nelder, J.A. 1961. The fitting of a generalization of the logistic curve. Biometrics. 17: 89-110.

Oliver, F.R. 1964. Methods of estimating the logistic function. Applied statistics. 13: 57-66.

Prajneshu, 1998. A Nonlinear Statistical Model for Aphid Population Growth. 
Jour. Inti. Soc. Ag. Statistics, 51(1): 7380.

Ratkowskay, D. A. 1983. Nonlinear Regression Modeling. New York. Marcel Dekker.

Richards, F.J. 1959. A flexible growth functions for empirical use. Journal of Experimental Botany. 10: 290-300.

\section{How to cite this article:}

Soumitra Sankar Das, Manoj Kanti Debnath, Satyananda Basak, Joydeb Ghosh and Aparajita Das. 2017. Estimation of Optimum Time of Spray for Controlling Rice Leaf Folder Infestation on Boro Rice in Terai Region of West Bengal Using Best Fitted Linear and Nonlinear Growth Model. Int.J.Curr.Microbiol.App.Sci. 6(6): 2300-2309. doi: https://doi.org/10.20546/ijcmas.2017.606.273 